\title{
Ex-appraisal bias: Negative illusions in appraising relationship quality retrospectively
}

\author{
Aidan P. J. Smyth \\ Johanna Peetz \\ Adrienne A. Capaldi \\ Carleton University, Canada \\ Journal of Social and Personal Relationships \\ DOI: 10.1177/0265407520907150
}

\begin{abstract}
Cognitive biases are prevalent within the context of romantic relationships. The present research investigated biases about relationships after they have ended. In a longitudinal design $(N=184)$, individuals reported relationship quality at two time points, as well as rated relationship quality retrospectively. Results supported an ex-appraisal bias: individuals rated their past relationship quality more negatively in retrospect than they had actually reported at the time. This bias was present across participants who stayed together and those who broke up but was three times larger for those whose relationships had ended. This bias may be a motivated cognition that helps individuals let go of their expartners after a breakup.

Keywords

Breakup, ex-appraisal bias, ex-partner, motivated cognition, retrospective bias, romantic Relationships

Corresponding author:

Aidan P. J. Smyth, Department of Psychology, Carleton University, 1125 Colonel By Drive, Ottawa, ON, Canada K1S 5B6. ORCID iD Aidan P. J. Smyth https://orcid.org/0000-0003-4382-1119

Email: aidan.smyth@carleton.ca

Funding

The author(s) disclosed receipt of the following financial support for the research, authorship, and/ or publication of this article: This research was supported by an insight grant from the Social Sciences and Humanities Research Council of Canada to Johanna Peetz.

Open research statement

As part of IARR's encouragement of open research practices, the authors have provided the following information: This research was not pre-registered. The data used in the research are available. The data can be obtained at: https://tinyurl.com/yjgx5k2f. The materials used in the research are available. The materials can be obtained at: https://tinyurl.com/yjgx5k2f.
\end{abstract}


The loving partner once seen as adventurous, spontaneous, and romantic is now remembered as the "ex" who was too reckless, disorganized, and selfish to contribute to a lasting relationship.

Relationships end frequently. While it is commonly estimated that half of marriages end in divorce (Amato, 2010), plenty of relationships dissolve before reaching the point of marriage: $86 \%$ of undergraduate students report experiencing at least one breakup in their lives (Battaglia et al., 1998). The way people think about their ex-relationshipsmatters. For example, the degree of attachment to the ex-partner or the frequency and content of thoughts about the ex-partner can determine emotional adjustment or recovery after breakup (Brenner \& Vogel, 2015; Fagundes, 2012; Sbarra, 2006). In the present research, we examined a cognitive bias about ex-relationships: the extent to which people change their appraisals of their relationships retrospectively, after they have ended.

Appraisals of relationships

Appraisals of relationships are subjective and biased by individuals' hopes and goals (e.g., love-is-blind bias; Gagn'e \& Lydon, 2004). For example, a common bias is to see your own relationship as better than other people's relationships (Martz et al., 1998; Murray et al., 2000) and as less likely to result in a breakup (Fowers et al., 1996). Individuals in satisfying relationships also tend to appraise their romantic partners in an idealized manner (Murray et al., 1996). These cognitive biases likely contribute to individuals' tendencies to appraise their relationships in a manner that is overly flattering but also contribute to relationship satisfaction (Murray et al., 1996). In sum, appraisals of relationships are subject to motivated cognition (Balcetis, 2008; Gagn'e \& Lydon, 2004). Importantly, the motivations underlying relationship appraisals may shift once a relationship ends.

Change in ex-relationship appraisals

There are several reasons to expect a change in relationship appraisal after a breakup.

First, some individuals may be less motivated to see their former relationships in the best possible light. Second, some individuals might even be motivated to see their ex-relationships in a negative light. Such a shift in motivation might help people cope with the breakup (see "psychological immune system"; Gilbert et al., 1998) and devalue a relationship that is no longer available to them. When a previously preferred option is no longer available, individuals tend to rate it more negatively (Brehm et al., 1966; Lyubomirsky \& Ross, 1999). This "sour grapes" pattern of shifts in appraisals has been shown in a (prospective) romantic relationship context: participants who were told their dating software "match" did not choose them for a date, rated this person as less attractive than did participants who were chosen (Wilson et al., 2004). In sum, there are several reasons to expect that on average, individuals may shift their appraisals of the quality of their romantic relationships toward a more negative view of the relationship after a breakup.

Change in ongoing relationship appraisals

There are also reasons to expect that even individuals in stable, continuing relationships may evaluate their past relationship quality more negatively in retrospect than they did at the time. A similar bias on the personal level has been identified for evaluations of the self over time (Christensen et al., 2003; Wilson \& Ross, 2001). For example, college students rated their past selves (four months ago) more negatively on a range of attributes than they had actually rated themselves at the time (Wilson \& Ross, 2001). This derogation of the past allowed them to perceive improvement in these attributes, as their current self compared favorably against the (overly negatively rated) past self and may be a selfenhancing mechanism (Wilson \& Ross, 2000). A similar retrospective bias might present in the 
evaluations of ongoing romantic relationships: fabricating a favorable downward comparison with the relationship in the past might create a sense of the relationship improving over time.

The present research

The primary purpose of the present research was to examine whether participants would show bias in their appraisals of their ex-relationships after a breakup. We examined this hypothesis using a prospective longitudinal design and expected that individuals would evaluate their ex-relationships more negatively in retrospect than they actually evaluated the relationships when they were still in them. A secondary purpose of this research was to investigate parallel changes in appraisal over time among individuals who remained with their romantic partners. Full materials and data are available here: https://tinyurl.com/yigx5k2f.

Method

Power analysis. To detect a small to medium $(f=.15)$ interaction effect of relationship status $x$ Time 1 versus Time 2 ratings with $80 \%$ power, a power analysis suggested a sample size of $N=90$, with $n=45$ participants per group. We aimed to recruit participants until the breakup group surpassed 45 participants (see more detail on the data collection here: https://tinyurl.com/yekl64ko). All data were collected before analysis. The final breakup group included 48 participants. A post hoc power sensitivity analysis suggests this sample is sufficient to detect within-subject effects of $d_{-} .41$ with $80 \%$ power.

Participants. We collected data from two undergraduate samples and one MTurk sample for the initial survey at Time 1 (total $N=540)$. Of these, 184 (34.1\%) completed the second survey at Time 2 . This retention rate is similar to previous studies (e.g., Spielmann et al., 2012: 38\% retention between surveys 3 months apart). Those who completed both surveys did not differ meaningfully from those who only completed the initial survey. The final sample included 184 participants (Mage $=27.03$ years, SD $=11.39$; $61 \%$ self-identified as female, $38 \%$ as male, $0 \%$ as "other," and $0.5 \%$ missing; $66 \%$ white; $95 \%$ heterosexual). On average, participants had been in relationships for 7.55 months ( $S D=5.08$; range: $1-$ 60 months) at Time 1.

Procedure. In the initial survey at Time 1 , participants completed a variety of measures, including a 6item measure of perceived relationship quality (short version of Fletcher et al., 2000, e.g., "I am satisfied with my relationship with my current romantic partner"), assessing satisfaction, commitment, intimacy, trust, passion, and love on scales ranging from $1=$ not at all to $7=$ extremely, which were averaged $(a=$ .91). They also completed a 7-item measure of perceived partner compatibility, rating compatibility in terms of personality traits, life goals, interests, core values, communication styles, and sexual styles (e.g., "[partner's name] and I fit well together in terms of our personality") on scales ranging from $1=$ strongly disagree to $7=$ strongly agree, which were averaged $(a=.91)$.

Four months later, participants were contacted by e-mail and invited to participate again. At Time 2, they reported whether they were still in the same relationship. Again, they completed a number of measures, including perceived relationship quality (Fletcher et al., 2000; 6 items; $a=.92$ ) and perceived partner compatibility ( 7 items; $a=.91$ ). They also completed retrospective evaluations of their relationship (e.g., "4 months ago, I was satisfied with my relationship with my (ex-) partner"; 6 items, a = .93) and retrospective compatibility (e.g., "4 months ago, [(ex-)partner's name] and I fit well together in terms of our personality," 7 items, a =.93). 
Results

At the second assessment, 48 participants (26.1\%) had experienced a breakup, while 136 (73.9\%) were still together with their partners. We explored whether those who broke up differed from those who did not at the initial time of assessment. Independent t-tests (equal variance not assumed) revealed that the breakup group was less satisfied than the still-together group at Time $1, t(81.57)=2.47, p=.015, d=.42$, but did not differ in perceived partner compatibility, $t(83.50)=1.03, p=.304, d=.17$ (see Table 1 for means).

We first examined bias in relationship appraisals. A 2 within-subject (perceived relationship quality: current T1 vs. retrospective T2) _ 2 between-subject (group: still together vs. broken up) analysis of variance (ANOVA) showed a main effect of relationship quality, $F(1,174)=45.40, p<.001, Z 2 p$ $=.207$, a main effect of group, $F(1,174)=20.70, p<.001, Z 2 p=.106$, and a significant interaction term, $F(1,174)=10.51, p=.001, Z 2 p=.057$ (Table 1 ).

Table I. Mean perceived relationship quality (RQ) and compatibility with partner (CP).

\begin{tabular}{|c|c|c|c|c|c|}
\hline & & \multicolumn{2}{|c|}{ Those who stayed together } & \multicolumn{2}{|c|}{ Those who broke up } \\
\hline & & M & $95 \% \mathrm{Cl}$ [LL; UL] & $M$ & $95 \% \mathrm{Cl}$ [LL; UL] \\
\hline Time I & Current RQ & 6.12 & {$[5.94 ; 6.30]$} & 5.63 & {$[5.31 ; 5.95]$} \\
\hline \multirow[t]{2}{*}{ Time 2} & Retrospective RQ & 5.74 & {$[5.55 ; 5.95]$} & 4.59 & {$[4.07 ; 5.1 \mathrm{I}]$} \\
\hline & Current RQ & 6.02 & {$[5.82 ; 6.22]$} & - & - \\
\hline \multicolumn{2}{|c|}{ Ex-appraisal bias (RQ) } & 0.36 & {$[0.20 ; 0.53]$} & 1.04 & {$[0.53 ; 1.55]$} \\
\hline Time I & Current CP & 5.67 & {$[5.5 \mathrm{I} ; 8.83]$} & 5.51 & {$[5.24 ; 5.78]$} \\
\hline \multirow[t]{2}{*}{ Time 2} & Retrospective $\mathrm{CP}$ & 5.36 & {$[5.17 ; 5.55]$} & 4.36 & {$[3.86 ; 4.86]$} \\
\hline & Current CP & 5.47 & {$[5.28 ; 5.66]$} & - & - \\
\hline \multicolumn{2}{|c|}{ Ex-appraisal bias (CP) } & 0.31 & {$[0.15 ; 0.47]$} & 1.13 & {$[1.62 ; 4.74]$} \\
\hline
\end{tabular}

Note. Ex-appraisal bias was calculated by subtracting ratings of retrospective RQ/CP at Time 2 from current $\mathrm{RQ} / \mathrm{CP}$ at Time I.

We also examined the bias in compatibility perceptions. A 2 within-subject (perceived partner compatibility: current T1 vs. retrospective T2) _ 2 between-subject (group: still together vs. broken up) ANOVA showed a main effect of compatibility rating, $F(1,174)=54.10, p<.001, Z 2 p=.237$, a main effect of group, $F(1,174)=12.11, p<.001, Z 2 p=.065$, and a significant interaction term, $F(1,174)=$ 17.56, $\mathrm{p}=.001, \mathrm{Z2p}=.092$ (Table 1). Participants judged their relationships more negatively and their partners as less compatible in retrospect than they had actually rated them at the time. This bias in appraisal was approximately three times larger for those whose relationships had ended than those who stayed together. In both groups and both outcome variables, the confidence intervals around the difference score mean did not include zero, suggesting that the appraisal bias was statistically significant. These results did not change when relationship length was included (see https://tinyurl.com/yz782vnk for details).

In line with the possibility that retrospective bias in ongoing relationships may be motivated by a desire to perceive improvement over time, individuals who stayed with their partners reported significantly greater relationship quality at Time 2 compared to the retrospective ratings, $t(130)=3.98, p<.001, d=$ .24 and marginally more compatibility at Time 2 compared to retrospective ratings, $t(130)=1.81, p=$ $.072, d=.10$ (i.e., they perceived improvement), although there was no actual difference between 
their relationship quality rating at Time 1 and Time $2, t(130)=1.01, p=.313, d=.09$, and they actually reported less compatibility with their partner at Time 2 than at Time $1, t(129)=2.52, p=.013, d=.20$.

\section{Discussion}

The present research indicated an ex-appraisal bias in that individuals appraised their relationships more negatively and remembered their ex-partners as less compatible in retrospect, after a breakup, than they had reported at the time they were still together. The present research also identified a shift in appraisal in ongoing relationships, similar to individuals' "derogation" of their past selves (Wilson \& Ross, 2001). At the later assessment, participants reported being significantly more satisfied with their relationship in the present than they recalled being four months earlier even though they had reported being equally happy at the time (i.e., an illusory improvement).

The change in appraisal of ex-relationships may reflect a protective function of the psychological immune system (Balcetis, 2008; Gilbert et al., 1998), which is comprised of various cognitive strategies (e.g., self-deception and positive illusions) that shield individuals from the emotional consequences of undesirable outcomes. A change in appraisal of an ex-relationship may allow individuals to better cope with a breakup. Indeed, qualitative research indicates that individuals reappraise how they think about their ex-relationships in order to adjust emotionally (Rollie \& Duck, 2006). Some researchers have even argued that people are unable to adjust to a breakup until they fundamentally change the way they view their ex-relationships (Bowlby, 1979; Fagundes, 2011). It is worth noting that the means for relationship quality in the present research all fall above the midrange of the scale, suggesting that participants did not completely derogate their relationships retrospectively; rather, their extreme positive view was tempered. It is an open question for future research which of these evaluations - while in the thick of a relationship or after the relationship has ended-is actually more accurate and less prone to motivated bias.

Memory bias may also contribute to the present findings. Memories of the past are often colored by feelings in the present (Christensen et al., 2003). Given that breakups are often accompanied by emotional distress (Brenner \& Vogel, 2015; Sbarra, 2006), the negative feelings surrounding the end of the relationship may color the appraisal of the entire relationship. Finally, an important avenue for future research may be the consequences of the ex-appraisal bias. Given that previous research has identified benefits associated with taking a negative view of an ex-relationship (e.g., breakup recovery and better subsequent relationships; Brenner \& Vogel, 2015; Spielmann et al., 2013), it is possible that the ex-appraisal bias is linked to positive outcomes both for the individuals' emotional adjustment after breakup and their subsequent relationships. 


\section{References}

Amato, P. R. (2010). Research on divorce: Continuing trends and new developments. Journal of Marriage and Family, 72(3), 650-666.

Balcetis, E. (2008). Where the motivation resides and self-deception hides: How motivated cognition accomplishes self-deception. Social and Personality Psychology Compass, 2(1), 361-381.

Battaglia, D. M., Richard, F. D., Datteri, D. L., \& Lord, C. G. (1998). Breaking up is (relatively) easy to do: A script for the dissolution of close relationships. Journal of Social and Personal Relationships, 15(6), 829-845.

Bowlby, J. (1979). The making and breaking of affectional bonds. Tavistock.

Brehm, J. W., Stires, L. K., Sensenig, J., \& Shaban, J. (1966). The attractiveness of an eliminated choice alternative. Journal of Experimental Social Psychology, 2(3), 301-313.

Brenner, R. E., \& Vogel, D. L. (2015). Measuring thought content valence after a breakup: Development of the positive and negative ex-relationship thoughts (PANERT) scale. Journal of Counseling Psychology, 62(3), 476-487.

Christensen, T. C., Wood, J. V., \& Barrett, L. F. (2003). Remembering everyday experience through the prism of self-esteem. Personality and Social Psychology Bulletin, 29(1), 51-62.

Fagundes, C. P. (2011). Implicit negative evaluations about ex-partner predicts breakup adjustment: The brighter side of dark cognitions. Cognition and Emotion, 25(1), 164-173.

Fagundes, C. P. (2012). Getting over you: Contributions of attachment theory for postbreakup emotional adjustment. Personal Relationships, 19(1), 37-50.

Fletcher, G. J., Simpson, J. A., \& Thomas, G. (2000). The measurement of perceived relationship quality components: A confirmatory factor analytic approach. Personality and Social Psychology Bulletin, 26(3), 340-354.

Fowers, B. J., Lyons, E. M., \& Montel, K. H. (1996). Positive marital illusions: Self-enhancement or relationship enhancement? Journal of Family Psychology, 10(2), 192-208.

Gagn'e, F. M., \& Lydon, J. E. (2004). Bias and accuracy in close relationships: An integrative review. Personality and Social Psychology Review, 8(4), 322-338.

Gilbert, D. T., Pinel, E. C., Wilson, T. D., Blumberg, S. J., \& Wheatley, T. P. (1998). Immune neglect: A source of durability bias in affective forecasting. Journal of Personality and Social Psychology, 75(3), 617-638.

Lyubomirsky, S., \& Ross, L. (1999). Changes in attractiveness of elected, rejected, and precluded alternatives: A comparison of happy and unhappy individuals. Journal of Personality and Social Psychology, 76(6), 988-1007.

Martz, J. M., Verette, J., Arriaga, X. B., Slovik, L. F., Cox, C. L., \& Rusbult, C. E. (1998). Positive illusion in close relationships. Personal Relationships, 5(2), 159-181.

Murray, S. L., Holmes, J. G., Dolderman, D., \& Griffin, D. W. (2000). What the motivated mind sees: Comparing friends' perspectives to married partners' views of each other. Journal of Experimental Social Psychology, 36(6), 600-620.

Murray, S. L., Holmes, J. G., \& Griffin, D. W. (1996). The benefits of positive illusions: Idealization and the construction of satisfaction in close relationships. Journal of Personality and Social Psychology, 70(1), 79-98.

Rollie, S. S., \& Duck, S. (2006). Divorce and dissolution of romantic relationships: Stage models and their limitations. In M. A. Fine \& J. H. Harvey (Eds.), Handbook of divorce and relationship dissolution (pp. 223-240). Lawrence Erlbaum.

Sbarra, D. A. (2006). Predicting the onset of emotional recovery following nonmarital relationship dissolution: A survival analyses of sadness and anger. Personality and Social Psychology Bulletin, 32, 298-312. 
Spielmann, S. S., Joel, S., MacDonald, G., \& Kogan, A. (2013). Ex appeal: Current relationship quality and emotional attachment to ex-partners. Social Psychological and Personality Science, 4(2), 175-180.

Spielmann, S. S., MacDonald, G., \& Tackett, J. L. (2012). Social threat, social reward, and regulation of investment in romantic relationships. Personal Relationships, 19(4),601-622.

Wilson, A. E., \& Ross, M. (2000). The frequency of temporal-self and social comparisons in people's personal appraisals. Journal of Personality and Social Psychology, 78(5), 928-942.

Wilson, A. E., \& Ross, M. (2001). From chump to champ: People's appraisals of their earlier and present selves. Journal of Personality and Social Psychology, 80(4), 572-584.

Wilson, T. D., Wheatley, T. P., Kurtz, J. L., Dunn, E. W., \& Gilbert, D. T. (2004). When to fire: Anticipatory versus postevent reconstrual of uncontrollable events. Personality and Social Psychology Bulletin, 30(3), 340-351. 